\title{
Homing in rocky intertidal fish. Are Lipophrys pholis L. able to perform true navigation?
}

\author{
P. E. Jorge $\cdot$ F. Almada $\cdot$ A. R. Gonçalves • \\ P. Duarte-Coelho $\cdot$ V. C. Almada
}

Received: 15 September 2011/Revised: 29 March 2012 / Accepted: 16 July 2012

(C) Springer-Verlag 2012

\begin{abstract}
Although navigation is common in many animals, only a few perform true navigation, meaning that they have the ability to return to a given place by relying on indirect cues obtained at the release site (i.e., by relying on information from a "map and compass" mechanism). The common intertidal fish, Lipophrys pholis, is thought to have homing abilities through a mechanism that primarily makes use of familiar landmarks (i.e., piloting). Anecdotal reports that individuals return to their home pools after release at unfamiliar sites suggest that $L$. pholis might use cues collected at the release site to find their way back (i.e., they might use map and compass information). Using a completely artificial setup, we tested the homing abilities of $L$. pholis as a function of age, sex, and familiarity with the release site. The findings showed that motivation for homing is present only in the adult phase and is independent of sex and/or familiarity with the release site. Moreover, adults released at a completely unfamiliar place oriented themselves in a direction roughly similar to that of their home pools. The fact that $L$. pholis were tested in a complete artificial environment means that hydrodynamic cues can be excluded as playing a role in this process and restricts the candidate options (e.g., magnetic cues). The ability to perform navigation based on a "map and compass" mechanism raises many interesting questions about
\end{abstract}

P. E. Jorge $(\square) \cdot$ F. Almada · A. R. Gonçalves .

P. Duarte-Coelho · V. C. Almada

Unidade Investigação Eco-Etologia, ISPA,

Instituto Universitário, R. Jardim do Tabaco, 34,

1149-041 Lisbon, Portugal

e-mail: pajorge@ispa.pt

P. E. Jorge

Biological Sciences Department, Virginia Tech,

4100 Derring Hall, Blacksburg, VA 24060, USA the learning process, once these individuals have restricted home ranges during their lives. In vertebrate navigation, the cues used during the navigation process are a question of debate, and L. pholis offers an outstanding model to test hypotheses and ultimately provide answers.

Keywords True navigation · Path integration · Landmarks $\cdot$ Navigational maps

\section{Introduction}

Homing is defined as the ability of an animal to return to its home place after displacement, frequently over considerable distances. According to Griffin (1952), determination of the direction of home can be based on the use of landmarks (piloting) or by relying on idiothetic information (path integration). Alternatively, animals can determine the direction of home by relying on the cues collected at the release site. In this last case, it is assumed that the animals preform true navigation (Griffin 1952), which implies the use of a "map and a compass" mechanism (Kramer 1959). The best-known examples of homing ability are among birds (e.g., homing pigeons, Wiltschko and Wiltschko 2003), but there are also good examples among amphibians (e.g., newts, Phillips and Borland 1994) and reptiles (e.g., sea turtles, Luschi et al. 2007; Lohmann et al. 2008a, b). Marine fish are no exception, as salmon return to their natal rivers to spawn (Dittman and Quinn 1996; Quinn 2005) and Atlantic cod return to their spawning grounds in the sea (Green and Wroblewski 2000; Rawson and Rose 2000; Robichaud and Rose 2001). However, the long-distance migration of fish makes it difficult to observe homing behavior and attempts to explain the homing orientation of migratory fish that have evoked a great variety of proposals 
regarding the sensory mechanisms involved (Mitamura et al. 2005). Moreover, the navigational cues used in the homing process seem to be the same as those used in migration (Wiltschko and Wiltschko 2003; Dittman and Quinn 1996), highlighting the role of homing animals in help deepening the knowledge on this behavior (Rodríguez et al. 2006).

In the marine intertidal zone, fishes from the families Gobiidae and Blenniidae are believed to have a good sense of geographic position (Almada et al. 1983; Arondson 1951; Gibson 1968). When chased in intertidal pools, they tend to use a limited number of escape itineraries and tend to seek shelter in sites with which they are familiar (Almada et al. 1983; Arondson 1951; Gibson 1968). If shelters were blocked, the fish often pushed against the obstructing material (Almada et al. 1983), which denotes a previous knowledge of these shelters and their relative positioning. Moreover, some rocky intertidal fish have been shown to have good homing abilities (Gibson 1967; Green 1971; Mitamura et al. 2005; Santos et al. 1989; Williams 1957). When displaced from their rocky pools, most of the fish can successfully return home (i.e., to the original pool).

Knowledge of the specific characteristics of a particular area, namely the location of refuges and preferential escape routes, plays an important role in the survival of these intertidal fish. Refuges in particular offer protection against predators or adverse weather conditions. According to Nieder (1993), these fish are not randomly distributed in the rock pools available in a given area; instead, each fish actively selects tide pools. Additionally, although pool fidelity may be observed (Almada et al. 1983), exploratory behavior, which occurs mainly during high tide (Almada et al. 1990b), may elicit their ability to memorize terrain characteristics outside the rock pool to which they are confined during low tide. Dodd et al. (2000) showed that individuals of the species Lipophrys pholis are able to quickly locate a refuge in a novel habitat by following a simple rule: swimming toward the nearest dark area. They are also able to memorize the position of a refuge based on conspicuous visual cues. Burt de Perera and Guilford (2008) showed that L. pholis are able to memorize and use spatial maps of local landmarks to learn the position of a refuge. These authors also showed that landmarks may consist of proximal cues located inside the pool inhabited by the fish or distal cues located outside the pool.

During the breeding season, L. pholis males usually guard their nests within crevices and holes or under stones where females lay their eggs (Almada et al. 1992). Males are territorial and defend their nests against conspecific competitors or potential predators, and they stay within the same pool or set of pools for extended periods of time (Faria and Almada 2006; Gibson 1968). One interesting characteristic of this fish is that nests are often placed in intertidal holes or crevices that become completely emersed for extended periods of time during low tide (Faria and Almada 2006). Morphological and physiological adaptations to the intertidal pseudo-amphibious behavior (Almada et al. 1990a, b, 1992), in addition to an ability to crawl on dry land propelled by the pectoral fins and body undulations (Almada et al. 1990b), make this species an outstanding biological model to study the homing behavior of fish and vertebrates in general.

Previous research has focused on the homing patterns, activity patterns, and habitat preferences of $L$. pholis. However, no studies have been undertaken to determine how this rocky pool fish finds its microhabitat and, more specifically, whether it performs navigation based on a map and compass mechanism (i.e., true navigation). In this study, we developed a new assay to experimentally test the navigational abilities of $L$. pholis. The findings provide robust evidence that adult fish display homing behavior and that they can perform navigation based on map and compass information.

\section{Methods}

\section{Subjects}

Individuals of the species L. pholis, a common fish in intertidal rock pools, were captured on rocky platforms at Cascais (S. Pedro, Portugal, $38^{\circ} 42^{\prime} \mathrm{N}, 9^{\circ} 22^{\prime} \mathrm{W}$ and Caso Raso, Portugal, $38^{\circ} 42^{\prime} \mathrm{N}, 9^{\circ} 29^{\prime} \mathrm{W}$ ) and tested in loco. The beach at $\mathrm{S}$. Pedro is surrounded by a high rocky cliff (height, $5 \mathrm{~m}$ ) and has an offshore direction (OD) that faces southwest $\left(220^{\circ}\right)$. At Cabo Raso, the rocky platform is not surrounded by any prominent cliff and/or other landmarks and has an OD that faces west $\left(270^{\circ}\right)$.

Specimens were collected using hand nets. After capture, each fish was transported in a transparent plastic container $(0.25 \mathrm{~m} \times 0.15 \mathrm{~m})$ filled with water from the pool where it was captured. All fish were then kept in a large opaque container $(0.45 \mathrm{~m}$ diameter $)$ filled with water collected from the place where they were tested. This container was situated next to the testing apparatus. Fish stayed in this last container for at least $10 \mathrm{~min}$ prior to be tested. Sexing and measuring were performed after individuals had been tested. For details about the methods used to determine the sex of these blennies, see Ferreira et al. (2010). Ontogenetic (Experiment 1 described below) and sex (Experiment 2 described below) differences in the homing behavior of $L$. pholis were tested. According to Gibson (1967), individuals can be considered to be adults when their total length is $\geq 8 \mathrm{~cm}$, immatures when their total length is between 5 and $8 \mathrm{~cm}$, and juveniles when their total length $\leq 5 \mathrm{~cm}$. 
Fig. 1 Experimental setup. Left, top view of the experimental apparatus; right, side view

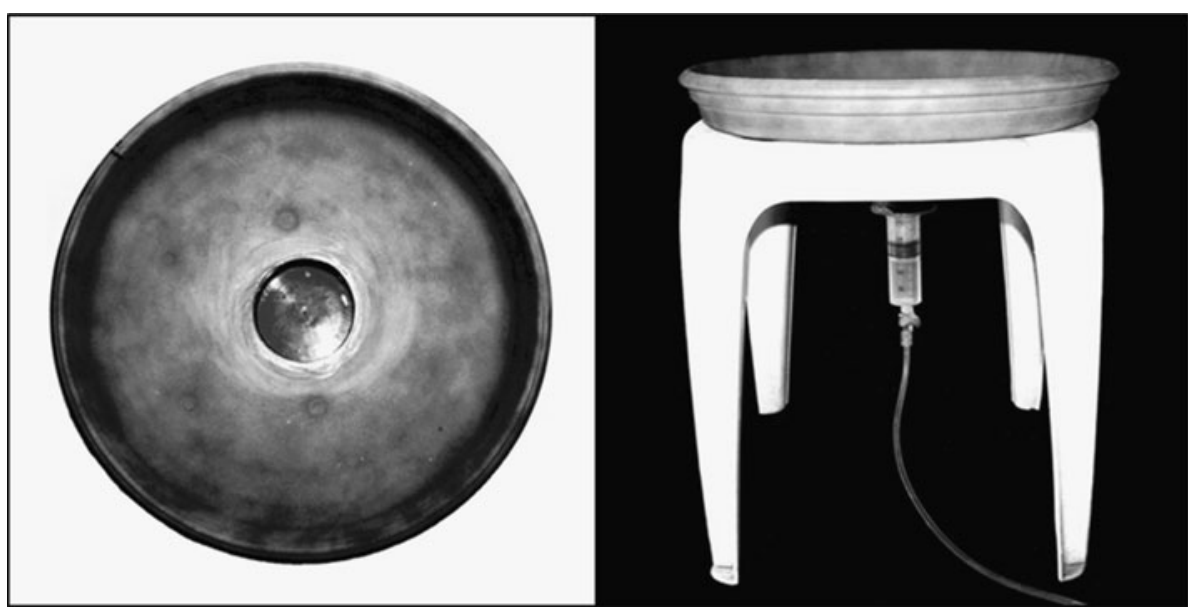

Testing

\section{Apparatus}

The testing apparatus consisted of a radially symmetric circular arena made of brown polyethylene (i.e., a commercially available plastic flower pot dish; diameter, $34 \mathrm{~cm}$ ) with a well drilled in the center (diameter, $8 \mathrm{~cm}$; depth, $4 \mathrm{~cm}$ ). The well allowed us to keep the fish in the center of the arena until the test was started (see Fig. 1). A hydraulic platform allowed release of the fish being tested. The apparatus was placed on top of a plastic bench, which kept it $30 \mathrm{~cm}$ above the ground. This and the border of the dish (i.e., in the center of the arena, the fish could not see the lower $5.7^{\circ}$ of the panorama) prevented the fish from using most of the local landmarks. Therefore, in the majority of the test situations, the arena provided a completely artificial environment to test the homing ability of individuals with potentially no visual landmarks available (however, see the exception reported in Experiment 1).
Moreover, the hydraulic platform was handled remotely from a distance of $5 \mathrm{~m}$, which prevented any interference with the fish's decision due to the presence of the observer.

\section{Experimental procedures}

The testing apparatus was placed in a central area of the intertidal rocky platform. It was leveled with a spirit level and filled with a 1-mm-deep layer of water from the waterfront next to it. Taking advantage of the ability of these fish to crawl when out of water (see "Introduction"), the water level inside the arena was kept to a minimum. This forces the fish to decide on a preferred vanishing direction within a reasonable time span. Fish were tested individually, and each fish was tested just once. Each fish was placed inside the well for $1 \mathrm{~min}$ after which time the hydraulic platform was raised and the fish released. Individuals were tested for $6 \mathrm{~min}$ total time $(1 \mathrm{~min}$ inside the well plus an additional $5 \mathrm{~min}$ for scoring). A valid score was defined as a fish reaching the wall of the arena within

Table 1 Initial orientation in L. pholis. $N$, number of individual fish tested; $n$, number of valid vanishing bearings obtained

\begin{tabular}{|c|c|c|c|c|c|c|}
\hline & \multirow[t]{2}{*}{ Group } & \multirow[t]{2}{*}{$N(n)$} & \multicolumn{2}{|c|}{ Mean vector } & \multirow[t]{2}{*}{$95 \% \mathrm{CI}$} & \multirow[t]{2}{*}{ Median score time } \\
\hline & & & $\alpha$ & $\mathrm{r}$ & & \\
\hline \multicolumn{7}{|c|}{ Experiment 1} \\
\hline OD $220^{\circ}$ & Immature & $16(9)$ & $135^{\circ}$ & 0.04 & - & $1: 13$ \\
\hline $\mathrm{SD} 120^{\circ}$ & Adult & $30(18)$ & $185^{\circ}$ & $0.48^{*}$ & $148^{\circ}-222^{\circ}$ & $0: 52$ \\
\hline \multicolumn{7}{|c|}{ Experiment 2} \\
\hline OD $270^{\circ}$ & Male & $25(9)$ & $244^{\circ}$ & 0.26 & - & $2: 18$ \\
\hline $\mathrm{SD} 120^{\circ}$ & Female & $8(8)$ & $337^{\circ}$ & 0.44 & - & $1: 33$ \\
\hline \multicolumn{7}{|c|}{ Experiment 3} \\
\hline h $109^{\circ}$ & Translocated & & & & & \\
\hline OD $270^{\circ}$ & Adults & $8(8)$ & $135^{\circ}$ & $0.81 * *$ & $104^{\circ}-167^{\circ}$ & 1:00 \\
\hline
\end{tabular}

$95 \%$ C. I. gives the 95 percent confidence interval of the mean vector. Median score time is given in minutes and seconds. $O D$ represents the offshore direction; $S D$, shadow direction; $h$, homeward direction. The significance of the mean value is given by the Rayleigh test. Asterisks, *, for $P$ values $<0.05$ and $* *$ for $P$ values $<0.01$ 
the 5-min interval; this corresponded to a path longer than the body length of even the largest individuals. The place where the fish touched the wall was considered to be the vanishing direction of that individual. The direction was determined with the help of a magnetic compass and was recorded to the nearest $5^{\circ}$. The time it took a fish to score was recorded with a stopwatch. Tests were performed on sunny days during the period of spring tides (i.e., full moon and new moon tides).

Experiment 1 was performed at S. Pedro beach. The navigational abilities of $L$. pholis were tested according to their ontogenetic development (i.e., immatures vs. adults). The testing apparatus was placed $10 \mathrm{~m}$ away from the cliff next to the waterfront, and individuals were collected in rocky pools from two opposite areas that were located approximately $50 \mathrm{~m}$ from the testing apparatus (mean directions: $155^{\circ}$ and $290^{\circ}$ ). The use of two opposite areas complies with the need to control for the use of landmarks by the tested animals. By pooling data from the two opposite sites, an observation of consistent orientation means that individuals were taking into account visual landmarks when determining the direction of vanish. Theoretically, in this situation, the mean vector for one site should cancel out the mean vector for the other site. A total of 46 individuals were tested: 15 immatures and 31 adults (see Table 1).

Experiment 2 was performed at Cabo Raso. Here, we tested the navigational abilities of both male and female adult individuals. Individuals were collected in rocky pools from two opposite areas (mean directions: $0^{\circ}$ and $190^{\circ}$ ). For collection details, see Experiment 1. In Experiment 1 at $\mathrm{S}$. Pedro, individuals could have used the rocky cliff along the upper part of the beach as a potential source of reference to keep track of their displacements. At Cabo Raso, no landmarks were visible from inside the testing apparatus. In addition, due to the orientation of the shoreline at Cabo Raso, the shadow direction inside the arena did not match any of the expected vanishing directions of the tested individuals. A total of 33 individuals were tested 25 males and 8 females (Table 1).

Experiment 3 was performed at Cabo Raso because we wanted to test the ability of $L$. pholis individuals to use geographic reference information from the navigational map. In Experiment 1 and 2, the fish might have been using path integration information to keep track of their displacements (maximum displacement length approximately $50 \mathrm{~m}$ ). Therefore, in this experiment, we increased the distance of displacement to $10.5 \mathrm{~km}$ (i.e., an unfamiliar area) and performed several detours along the displacement to the release site. Adult L. pholis individuals were collected at S. Pedro beach one day and tested the next day at Cabo Raso (home direction, $109^{\circ} \mathrm{N}$ ). To avoid integration of the path during transport, in addition to the detours mentioned above, fish were kept in water containers filled with water from their original pools. In mice, animals transported inside their nests failed to integrate the displacement (Alyan 1996). Moreover, L. pholis individuals were transported to the release site with no access to visual cues throughout the entire outward journey, as such cues are essential to correct errors of the path integrator in cases of displacement with tortuous detours (Etienne et al. 2004; Collett and Graham 2004). Together, these procedures make path integration information potentially unusable. After arriving at Cabo Raso, the fish container was placed on the rocky intertidal platform and the water was replaced with new water from the test site. The test started $1 \mathrm{~h}$ after arrival.

\section{Statistical analysis}

Directional data were analyzed and were characterized by the mean vector (direction $\alpha$ and length $r$ ), the deviation of the mean direction from the offshore direction (OD, here represented as perpendicular to the shoreline direction), the shadow direction that could bias our results (SD, shadow created by the border of the testing dish in the early hours of the morning) and home direction ( $h$, direction of the rock pool where each fish was collected). The significance of the mean vector was determined using the Rayleigh test. The $95 \%$ confidence interval was used to test whether the mean vector of each group included the expected homing direction. Differences in direction and distribution between groups were analyzed using the Watson William test and the Mann-Whitney test, respectively. For additional information, see Batschelet (1981).

\section{Results}

The initial orientation and performance of each group in the three sets of experiments are shown in Table 1 and pooled data in Figs. 3 and 5. In Experiment 1, we tested the ontogenetic development of homing behavior in L. pholis (Figs. 2, 3). Because we balanced the number of individuals tested from each side of the testing arena, we expected an initial random orientation of the potted data (Fig. 2). Bearings from individuals with opposite expected directions should cancel each other out (see "Methods"). This allows us to control for other types of orientation (e.g., the use of shadows as potential refuges; Dodd et al. 2000; Burt de Perera and Guilford 2008). In the present experiments, this could have affected the decision of the tested individuals because the rim of the dish introduced a small shadow in the arena.

When the data were potted with reference to the geographic north, the adult group exhibited consistent 


\section{A}

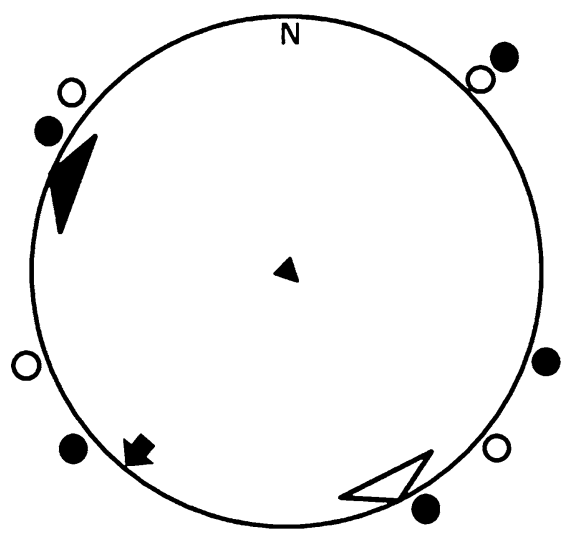

Fig. 2 Ontogeny of the homing behavior in L. pholis. a Initial orientation of immature fish. b Initial orientation of adult fish. Symbols plotted on the periphery of the circle represent the individual vanishing bearings of each tested fish. Solid inner arrow, offshore direction, Triangles at the edge of each diagram indicate the direction of the home pools. The solid triangle shows home pool direction of

\section{A}

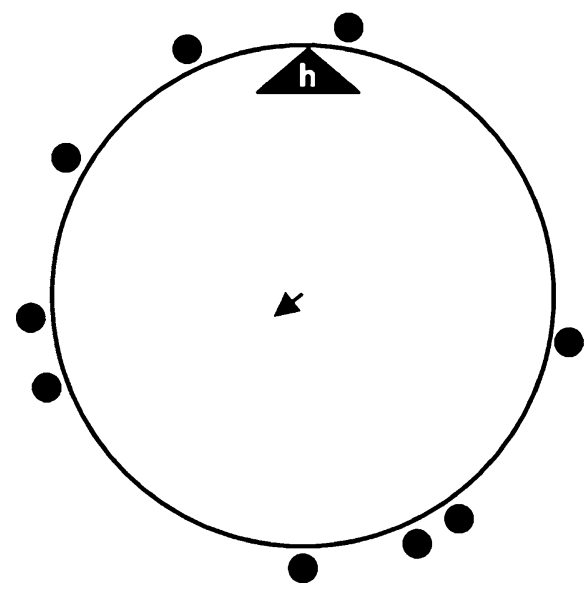

Fig. 3 Ontogeny of the homing behavior in L. pholis having the home pools as reference. a Initial orientation of immature fish. b Initial orientation of adult fish. Symbols plotted on the periphery of the circle represent the individual vanishing bearings of each tested fish relative to its home pool. The triangle at the edge of each diagram

orientation (Fig. 2b), whereas the immature group was disoriented (Fig. 2a). In adults, the $95 \%$ confidence interval of the mean vector did not include the direction of the shadow (see Table 1; Fig. 2b). Moreover, when data were pooled with reference to the home pool direction (Fig. 3), the adult group again showed significant orientation relative to the home pools (Fig. 3b), whereas the immature group failed to orient on both occasions (Figs. 2a, 3a). Significant differences in the distribution of the two groups (immatures vs. adults) when bearings were

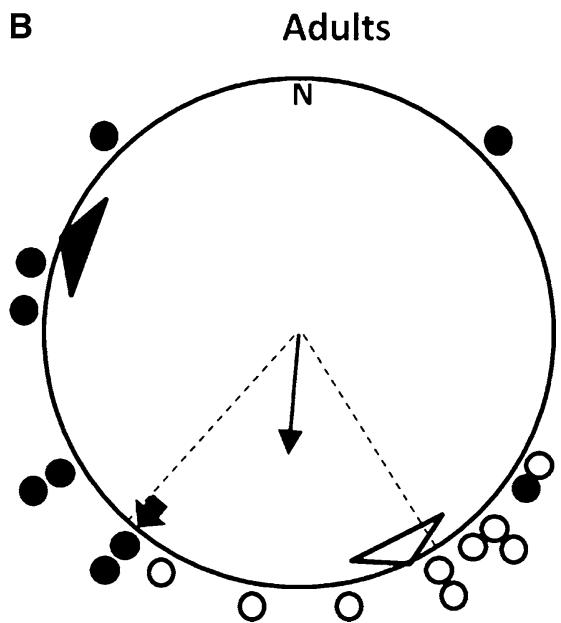

solid symbols, and the open triangle shows the home pool direction of the open symbols. The vector radiating from the center indicates the mean vanishing vector of the group. Dashed lines represent the $95 \%$ confidence interval of the mean vector, shown when the mean vector is significant. $N$ represents the geographic North direction

B

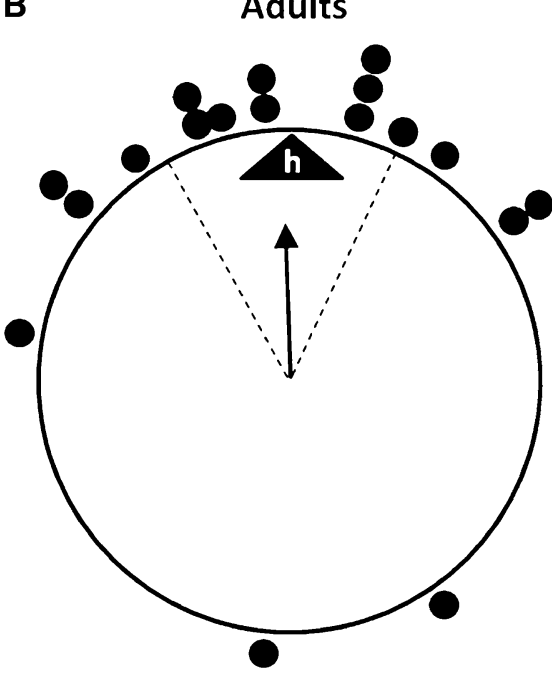

indicates the direction of the home pools. The vector radiating from the center indicates the mean vanishing vector of the group. Dashed lines represent the $95 \%$ confidence interval of the mean vector, shown when the mean vector is significant

referenced to the home pool directions (Mann-Whitney test, $\left.U_{(18,9)}=2.263, P<0.05\right)$.

In Experiment 2, we tested the homing abilities of adult males and females (Figs. 4, 5). As in Experiment 1, referencing data to the geographic north should produce random orientation of the analyzed groups. Consistent with this prediction, both groups fail to exhibit consistent orientation (Table 1; Fig. 4). Conversely, when the data were pooled with the direction of the home pools as reference, both adult males and adult females showed significant 
A

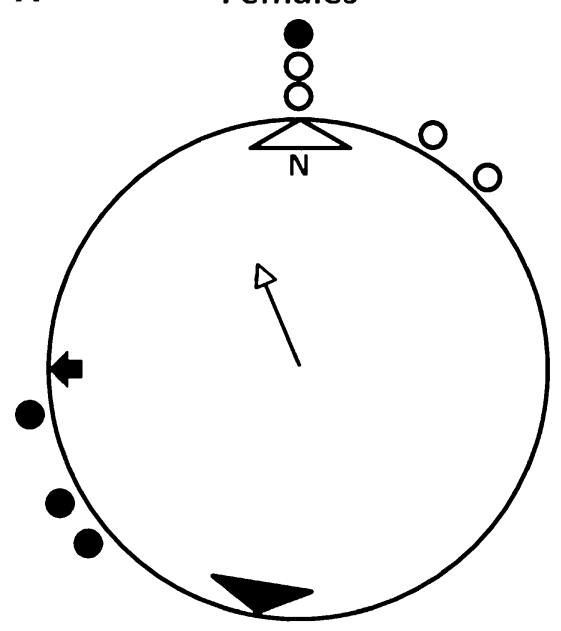

Fig. 4 Homing behavior of both male and female adult L. pholis. a Initial orientation of adult females. b Initial orientation of adult males. Symbols plotted on the periphery of the circle represent the individual vanishing bearings of each tested fish. Solid inner arrow, offshore direction, Triangles at the edge of each diagram indicate the direction of the home pools. The solid triangle shows the home pool

orientation (Fig. 5). Moreover, no difference was found between the mean directions of the two groups (MannWhitney test, $P>0.05$ ).

In Experiment 3, we tested the homing abilities of adult fish released in an unfamiliar area (Fig. 6). The group showed consistent orientation (Table 1; Fig. 6) that matched the expected home direction (i.e., the $95 \%$ confidence interval of the mean vanishing direction included the expected geographic home direction; see Fig. 6).
B

Males

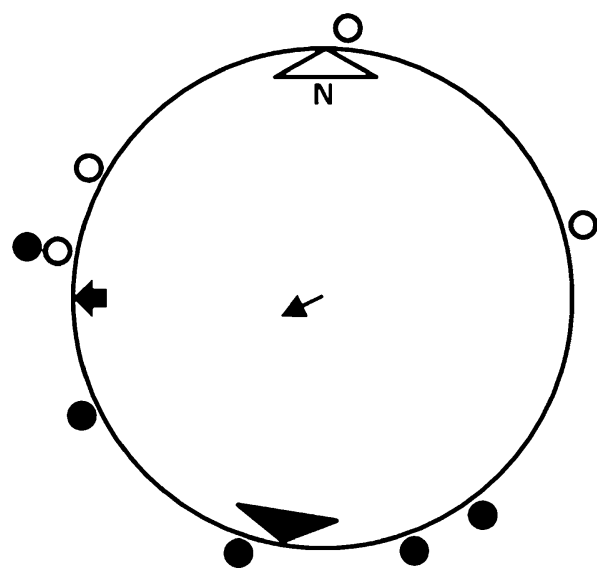

direction of solid symbols and the open triangle shows the home pool direction of the open symbols. The vector radiating from the center indicates the mean vanishing vector of the group. Dashed lines represent the $95 \%$ confidence interval of the mean vector, shown when the mean vector is significant. $N$ represents the geographic North direction

Moreover, these fish did not show the spontaneous orientation exhibited by adult fish in Experiment 1 (see Fig. 2b).

\section{Discussion}

Our findings show that in L. pholis, homing behavior inside a familiar area can be processed independent of the presence of visual landmarks. The good homeward orientation

\section{A}

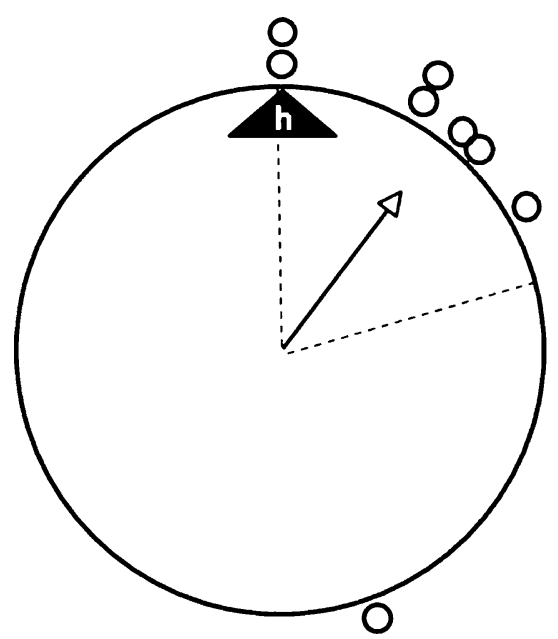

B

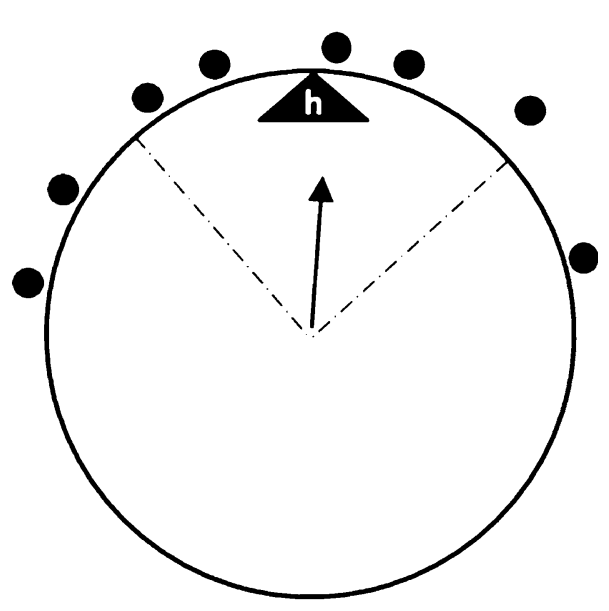

each diagram indicates the direction of the home pools. The vector radiating from the center indicates the mean vanishing vector of the group. Dashed lines represent the $95 \%$ confidence interval of the mean vector, shown when the mean vector is significant 


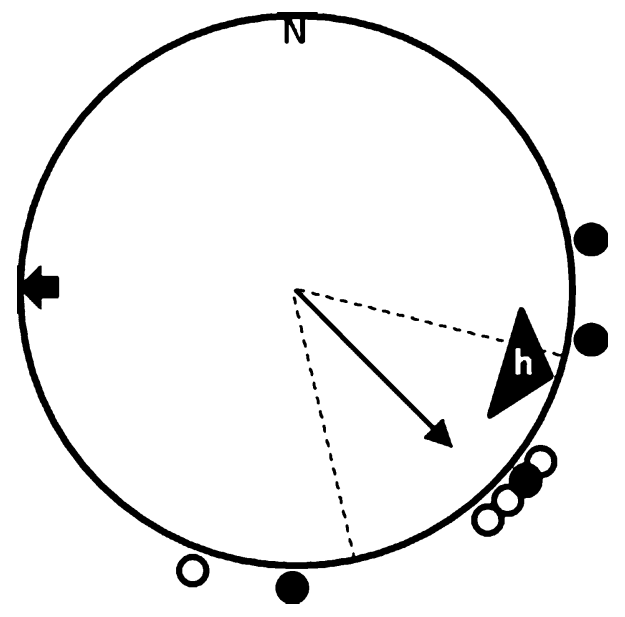

Fig. 6 True navigation in L. pholis. Symbols at the periphery of the circle represent the individual vanishing bearings of the tested fishes, and the vector radiating from the center shows the mean vanishing bearing of the group. Dotted lines represent the $95 \%$ confidence interval of the mean vector. Solid inner arrow, offshore direction; open inner triangle, expected home direction. Solid symbols represent adult male fishes and open symbols, adult female fishes

exhibited by adult fish when tested in a completely artificial environment indicates that the homing mechanism is also independent of hydrodynamic movements (a potential source of reference for marine fish) generated along the coast line. This suggests that inside the familiar area, the homing ability displayed by L. pholis may be mediated by mechanisms other than visual cues or topographic memorization. More interestingly, when transported to a distant unfamiliar area in a way that potentially made route information unreliable, L. pholis was able to perform homing behavior. The only way to obtain navigational information at an unfamiliar release site is to rely on referenced information from the navigational map. Thus, this result suggests that like many other vertebrates (e.g., newts, salmons, homing pigeons, and sea turtles), L. pholis uses a map and compass mechanism when determining the homeward direction.

Our findings show that adult $L$. pholis can orient themselves toward their home pools, whereas immatures failure to orient (Fig. 3). This suggests that motivation for homing may begin with the onset of sexual maturation and not during a hypothetical imprinting phase during larval development, as is the case in some other marine species (e.g., Dittman and Quinn 1996; Lohmann et al. 2008a, b). Choosing and maintaining good shelters or nestling holes can be of primordial importance for adults during the reproductive season, and therefore, site fidelity to a known area may be selectively advantageous. Several studies report that during the breeding season while males guard nests, females search the area in an attempt to find appropriate nests or males for laying their eggs (Almada et al. 1990b; Qasim 1957). The ability to use a spatial map of visual cues (e.g., topographic features) provides an advantage because it enables the fish to keep track of its position in a familiar area. The consistent orientation of adults in Experiment 1 (Fig. 2b) can be explained by the use of the rocky cliff on the upper part of the beach at $S$. Pedro as a visual landmark. This hypothesis is supported by the results of Experiment 2: At Cabo Raso, where no landmarks were available, adults showed no consistent orientation (Fig. 4). In both cases, random orientation was expected, since we tested individuals that were collected from the rocky platform from both sides of the testing arena. The mean result of expected opposite bearings should be null (see "Methods").

If the use of prominent landmarks can explain the consistent spontaneous orientation observed in Experiment 1 (Fig. 2b), it cannot account for the good orientation toward the home pools observed in both Experiments 1 and 2 (Figs. 3b, 5). This result suggests that the ability of $L$. pholis to memorize spatial maps of familiar areas based on visual cues of conspicuous landmarks (Burt de Perera and Guilford 2008; Dodd et al. 2000) may be the part of the mechanism by which these fish keep track of their movements (i.e., displacements), though landmarks are not the only cues being processed by these fish.

In a complex environment like the intertidal zone that experiences cyclic changes in water level, salinity, and temperature, path integration may provide the information needed to find the straightest route to a refuge or a specific pool. However, path integration information by itself has a great disadvantage when compared with map information because it does not allow for correction of errors (Etienne et al. 1998). Drifts in the fish's movement due to water currents in addition to constant detours along the path make the path integration strategy potentially unhelpful. However, the combination of information obtained from the spatial map of visual landmarks and information obtained from the path integrator provides a way to correct for errors (Collett and Graham 2004). For example, in hamsters, visual landmarks reset the path integrator. When testing the homing behavior of golden hamsters in a circular arena in which the position of the nest can be rotated relative to the departure point, Etienne et al. (2004) showed that in continuous darkness, the hamsters returned to their point of departure at the rotated nest and therefore depended on path integration only. However, if visual cues from the room were briefly presented, the animals headed for the usual nest location, as defined by room cues, showing that landmarks can reset the path integrator.

If this mechanism (see above) provides an excellent navigational system for navigation in familiar areas, it cannot account for navigation in unfamiliar areas where landmarks are not known. True navigation implies that 
animals orient themselves by relying on cues available at the unfamiliar release site, and these usually are cues with a worldwide geographic distribution such as magnetic cues (Wiltschko and Wiltschko 1995; Lohmann 1991), lightdependent cues (Muheim et al. 2006; Phillips et al. 2010), infrasound cues (Hagstrum 2000), or odor cues (Jorge 2011; Wallraff 2005). In Experiment 3, we showed that adult L. pholis were able to orient themselves toward their home areas even if they were placed in an unfamiliar distant area, and they did so by relying on cues available in the unfamiliar area (Fig. 6). During the outward journey to the release site, we performed several detours with the objective of making path integration information unreliable for determining the home direction. Therefore, to correctly determine the home direction in Experiment 3, individuals must have used map information. This result raises several interesting questions, such as which cues are being used (see above alternative options) for homing and how the fish learn the distribution of those cues, because in natural conditions, they have restricted home ranges. In other vertebrates, magnetic cues are the most likely candidates for forming the navigational map. However, given the short range of displacement performed by this species, other cues might be more reliable (e.g., odors dissolved in the water). Several studies have pointed out that an intact olfactory system is needed for navigation (Mitamura et al. 2005, for review see Wallraff 2005). However, as shown recently in homing pigeons, olfactory cues are needed to activate the navigational system but not to provide map information (Jorge et al. 2009, 2010; Jorge 2011). Beyond the discussion of which cue or set of cues is the most likely candidates to provide navigational information, the results presented here show that $L$. pholis can navigate from unfamiliar areas based on a navigational map and thus that they can perform true navigation.

Acknowledgments PEJ was supported by grant SFRH/BPD/64087/ 2009; FA by grant SFRH/BPD/63170/2009; and AG by grant SFRH/ BD/42226/2007, all from the Portuguese Science Foundation (FCT). The UIE-ISPA is funded by FCT through the pluri-annual and programmatic funding scheme (FEDER) as research unit \#331/94.

\section{References}

Almada V, Dores J, Pinheiro A, Santos RS (1983) Contribuição para o estudo do comportamento de Coryphoblennius galerita (L.) (Pisces: Blenniidae). Mem Mus Mar Ser Zool 2:1-165

Almada VC, Barata E, Gonçalves EJ, Oliveira R (1990a) On the breeding season of Lipophrys pholis (Pisces: Blenniidae) at Arrábida, Portugal. J Mar Biol Assess UK 70:913-916

Almada VC, Oliveira R, Barata E, Gonçalves EJ, Rito A (1990b) Field observations on the behaviour of the breeding males of Lipophrys pholis (Pisces: Blenniidae). Portugaliae Zoologica 1:27-36

Almada VC, Gonçalves EJ, Oliveira RF, Barata EN (1992) Some features of the territories in the breeding males of the intertidal blenny Lipophrys pholis (Pisces: Blenniidae). J Mar Biol Assoc UK 72:187-197

Alyan SH (1996) Evidence for resetting the directional component of path integration in the house mouse (Mus musculus). Ethology 102:629-638

Arondson IR (1951) Orientation and jumping behavior in the gobiid fish Bathygobius soporator. Amer Mus Novit 1480:1-22

Batschelet E (1981) Circular statistics in biology. Academic Press, London

Burt de Perera T, Guilford TC (2008) Rapid learning of shelter position in an intertidal fish, the shanny Lipophrys pholis L. J Fish Biol 72:1386-1392

Collett TS, Graham P (2004) Animal navigation: path integration, visual landmarks and cognitive maps. Curr Biol 14:R475-R477

Dittman AH, Quinn TP (1996) Homing in Pacific salmon: mechanisms and ecological basis. J Exp Biol 199:83-91

Dodd J, Gibson RN, Hughes RN (2000) Use of cues by Lipophrys pholis L. (Teleostei, Blenniidae) in learning the position of a refuge. Behav Process 49:69-75

Etienne AS, Maurer R, Berlie J, Georgakopoulos J, Reverdin B, Rowe T, Séguinot V (1998) Navigation through vector addition. Nature 396:161-164

Etienne AS, Maurer R, Boulens V, Levy A, Rowe T (2004) Resetting the path integrator: a basic condition for route-based navigation. J Exp Biol 207:1491-1508

Faria C, Almada V (2006) Patterns of spatial distribution and behaviour of fish on a rocky intertidal platform at high tide. Mar Ecol Prog Ser 316:155-164

Ferreira F, Santos MM, Reis-Henriques MA, Vieira NM, Monteiro NM (2010) Sexing blennies using genital papilla morphology or ano-genital distance. J Fish Biol 77:1432-1438

Gibson RN (1967) Studies on the movements of littoral fish. J Anim Ecol 36:215-234

Gibson RN (1968) The agonistic behavior of juvenile Blennius pholis L. (Teleostei). Behaviour 30:192-217

Green JM (1971) High tide movements and homing behavior of the tidepool sculpin Oligocottus maculosus. J Fish Res Board Can 28:383-389

Green JM, Wroblewski JS (2000) Movement patterns of Atlantic cod in Gilbert Bay, Labrador: evidence for bay residency and spawning site fidelity. J Mar Biol Assoc UK 80:1077-1085

Griffin DR (1952) Bird navigation. Biol Rev Camb Philos Soc 27:359-400

Hagstrum JT (2000) Infrasound and the avian navigational map. J Exp Biol 203:1103-1111

Jorge PE (2011) Odors in the context of animal navigation. In: Weiss LE, Atwood JM (eds) The biology of odors. Nova Science Publishers Inc, New York, pp 207-226

Jorge PE, Marques AE, Phillips JB (2009) Activational rather than navigational effects of odors on young pigeons homing. Curr Biol 19:650-654

Jorge PE, Marques PAM, Phillips JB (2010) Activational effects of odours on avian navigation. Proc R Soc B 277:45-49

Kramer G (1959) Recent experiments on bird orientation. Ibis 101:399-416

Lohmann KJ (1991) Magnetic orientation by hatchling loggerhead sea turtles (Caretta caretta). J Exp Biol 155:37-49

Lohmann KJ, Luschi P, Hays CG (2008a) Goal navigation and islandfinding in sea turtles. J Exp Mar Biol Ecol 356:83-95

Lohmann KJ, Putman NF, Lohmann CMF (2008b) Geomagnetic imprinting: a unifying hypothesis of long-distance natal homing in salmon and sea turtles. Proc Natl Acad Sci 105:1909619101

Luschi P, Benhamou S, Girard C, Ciccione S, Roos D, Sudre J, Benvenuti S (2007) Marine turtles use geomagnetic cues during open-sea homing. Curr Biol 17:126-133 
Mitamura H, Arai N, Sakamoto W, Mitsunnaga Y, Tanaka H, Mukai Y, Nakamura K, Sasaki M, Yoneda Y (2005) Role of olfaction and vision in homing behaviour of black rockfish Sebastes inermis. J Exp Mar Biol Ecol 322:123-134

Muheim R, Phillips JB, Akesson S (2006) Polarized light cues underlie compass calibration in migratory songbird. Science 313:837-839

Nieder J (1993) Distribution of juvenile blennies (Pisces, Blenniidae) in small tide-pools: result of low-tide lottery or strategic habitat selection. Bonn Zool Beitr 44:133-140

Phillips JB, Borland SC (1994) Use of a specialized magnetoreception system for homing by the eastern red-spotted newt Notophthalmus viridescens. J Exp Biol 188:275-291

Phillips JB, Muheim R, Jorge PE (2010) A behavioral perspective on the biophysics of the light-dependent magnetic compass: a link between directional and spatial perception? J Exp Biol 213:3247-3255

Qasim SZ (1957) The biology of Blennius pholis L (Teleostei). Proc Zool Soc Lond 128:161-208

Quinn TP (2005) The behavior and ecology of Pacific Salmon and Trout. University of Washington Press, Seattle

Rawson GL, Rose GA (2000) Seasonal distribution and movements of coastal cod (Gadus morhua L.) in Placentia Bay, Newfoundland. Fish Res 49:61-75
Robichaud D, Rose GA (2001) Multiyear homing of Atlantic cod to spawning ground. Can J Fish Aquat Sci 58:2325-2329

Rodríguez F, Broglio C, Durán E, Gómez A, Salas C (2006) Neural mechanisms of learning in teleost fish. In: Brown C, Laland K, Krause J (eds) Fish cognition and behaviour. Blackwell, Oxford, pp 243-277

Santos RS, Almada VC, Santos AJ (1989) Field experiments and observations on homing and territoriality in intertidal blennies. In: Blanchard RJ, Brain PF, Blanchard DC, Parmigiani S (eds) Ethoexperimental approaches to the study of behaviour. Kluwer Academic Publishers, vol 48, pp 623-632

Wallraff HG (2005) Avian navigation: Pigeon homing as a paradigm. Springer, Berlin

Williams GC (1957) Homing behavior of California rocky shore fishes. Univ Calif Publ Zool 59:249-284

Wiltschko R, Wiltschko W (1995) Magnetic orientation in animals. Springer, Berlin

Wiltschko R, Wiltschko W (2003) Avian navigation: from historical to modern concepts. Anim Behav 65:257-272 